\title{
Cross sectional echocardiographic and angiocardiographic correlation in criss cross hearts
}

\author{
PETER J ROBINSON, VACHERA KUMPENG, FERGUS J MACARTNEY \\ From the Hospital for Sick Children, London
}

SUMMARY Cross sectional echocardiography can provide accurate anatomical diagnosis in congenital heart diseases and therefore should be able reliably to identify criss cross hearts and enable the analysis of their sequential arrangement non-invasively. The cross sectional echocardiographic diagnoses in eight consecutive patients with this condition were compared with those made at cardiac catheterisation and cineangiocardiography (five retrospectively, three prospectively). The mean number of invasive studies required to reach the diagnosis was 1.9 (range 1-4). Complete anatomical diagnosis was achieved with cross sectional echocardiography in all patients, but identification of ventricular morphology was much more straightforward using cineangiocardiography. If the transducer was held steady in either a precordial or subcostal position and rocked anteriorly and posteriorly the characteristic crossing over of the ventricular inflows could easily be seen. In no plane was there normal parallel arrangement of ventricular inflows.

A complete diagnosis should be possible in these patients using cross sectional echocardiography in experienced hands and at a single session in the cardiac catheterisation laboratory.

Criss cross heart is a rare rotational abormality of the heart in which systemic and pulmonary venous streams cross without mixing at atrioventricular valve level. ${ }^{1}$ As this definition suggests, it is an abnormality of relation rather than connection ${ }^{2}$ but is often associated with abnormalities of connection, and usually accompanies other complex intracardiac anomalies. ${ }^{3-8}$ The ventricles are most often arranged in a relatively superoinferior fashion with the right sided atrium connecting with the left sided ventricle, and the left sided atrium with the right sided ventricle. Establishment of the precise type and mode of atrioventricular connection may not be achieved unless multiple angiocardiograms, with varying projections and sites of injection, are used. Thus repeated cardiac catheterisations may be required before the precise diagnosis is established. ${ }^{4}$

A single case report of the cross sectional echocardiographic diagnosis of criss cross heart has recently been published. 9 To assess the relative roles of cross sectional echocardiography and angiocardiography in this condition we reviewed the cases seen at this hospital since 1980 and compared our cross sectional

Requests for reprint to Professor F J Macartney, The Hospital for Sick Children, Great Ormond Street, London WCIN 3JH.

Accepted for publication 5 March 1985 echocardiographic diagnoses with the findings at cardiac catheterisation and angiocardiography.

\section{Patients and methods}

Eight patients with this condition have been seen since January 1980 (four male, four female) aged 6 weeks to 12 years (median 3.5 years) at initial presentation. Cross sectional echocardiography, cardiac catheterisation, and cineangiocardiographic records were retrospectively reviewed in five patients. Three further patients were examined prospectively during the time of the study using our standard echocardiographic protocol. ${ }^{10}$

Cardiac catheterisation was performed using standard techniques with $1-4$ (mean 1.9) studies required per patient before a definitive diagnosis was made. In all patients recognition of the criss cross had been assisted either by right atrial or caval injections or by follow through opacification of the left atrium and ventricle. Cross sectional echocardiographic studies were performed with an ATL (Advanced Technology Laboratory) Mark V mechanical sector scanner and a 3 or $5 \mathrm{MHz}$ transducer in four patients, a Toshiba SSH 20 system with a $2.5 \mathrm{MHz}$ transducer in one patient, and an ADR 4000S mechanical sector scanner with a $3 \mathrm{MHz}$ transducer in the last three patients. The resulting videotapes were reviewed. Echocar- 
Table Invasive and non-invasive findings

\begin{tabular}{|c|c|c|c|c|c|c|c|c|c|c|}
\hline \multirow{2}{*}{$\begin{array}{l}\text { Case } \\
\text { No }\end{array}$} & \multirow[t]{2}{*}{ Age } & \multirow[t]{2}{*}{ Sex } & \multicolumn{8}{|c|}{ Cross sectional echocardiography } \\
\hline & & & Situs & $\begin{array}{l}A V \\
\text { connection }\end{array}$ & $R A V V$ & $L A V V$ & $V S D$ & RVOTO & $\begin{array}{l}V A \\
\text { connection }\end{array}$ & $\begin{array}{l}\text { Gt vessel } \\
\text { position }\end{array}$ \\
\hline 1 & 5 mnth & $\mathbf{M}$ & Solitus & C & $\mathbf{N}$ & $\mathbf{N}$ & $\begin{array}{c}\text { Perimembranous } \\
\text { inlet outlet }\end{array}$ & Valvar, subvalvar & D & Ao anterior an $\frac{\bar{C}}{\bar{C}}$ \\
\hline 2 & $4 \mathrm{yr}$ & $\mathbf{F}$ & Solitus & C & $\mathbf{N}$ & $\mathbf{S}$ & $\begin{array}{l}\text { Perimembranous } \\
\text { inlet outlet }\end{array}$ & - & C & Ao anterior an \\
\hline 3 & $5 \mathrm{yr}$ & $\mathbf{M}$ & Solitus & C & $\mathbf{N}$ & $\mathbf{N}$ & Trabecular inlet & Subvalvar & D & Side by side, \\
\hline 4 & $6 \mathrm{wk}$ & $\mathbf{F}$ & Solitus & C & $\mathbf{N}$ & $\mathbf{S}$ & $\begin{array}{l}\text { Perimembranous } \\
\text { inlet }\end{array}$ & - & D & Ao anterior an \\
\hline 5 & $1 \mathrm{yr}$ & $\mathbf{M}$ & Solitus & C & $\mathbf{N}$ & $\mathbf{N}$ & $\begin{array}{l}\text { Perimembranous } \\
\text { inlet outlet }\end{array}$ & - & D & Ao anterior an \\
\hline 6 & $3 \mathrm{yr}$ & $\mathbf{F}$ & Solitus & D & $\mathbf{N}$ & $\mathbf{N}$ & $\begin{array}{l}\text { Perimembranous } \\
\text { inlet outlet }\end{array}$ & - & DORV & Ao anterior an \\
\hline $\begin{array}{l}7 \\
8\end{array}$ & $\begin{array}{l}12 \mathrm{yr} \\
10 \mathrm{yr}\end{array}$ & $\begin{array}{l}\mathbf{F} \\
\mathbf{M}\end{array}$ & $\begin{array}{l}\text { Solitus } \\
\text { Solitus }\end{array}$ & $\stackrel{\mathrm{C}}{\mathrm{C}}$ & $\stackrel{\mathbf{N}}{\mathbf{N}}$ & $\begin{array}{l}\mathbf{N} \\
\mathbf{S}\end{array}$ & $\begin{array}{l}\text { Perimembranous } \\
\text { Perimembranous } \\
\text { inlet outlet }\end{array}$ & - & $\begin{array}{l}\mathrm{C} \\
\mathrm{C}\end{array}$ & $\begin{array}{l}\text { Ao anterior an } \\
\text { Ao posterior at }\end{array}$ \\
\hline
\end{tabular}

-, absent; Ao, aorta; AV, atrioventricular; C, concordance; D, discordance; DORV, double outlet right ventricle; Gt vessel position, great position in relation to each other; $\mathrm{L}$, left; LAVV, left atrioventricular valve; $N$, normal; $\mathrm{O}$, override; $\mathbf{R}$, right; RAVV, right atrioventricular RVOTO, right ventricular outflow tract obstruction; S, stenotic; VA, ventriculoarterial; VSD, ventricular septal defect.

diographic and angiocardiographic opinions were reached by consensus between us. Two patients died; in one the heart was available for detailed necropsy.

\section{Results (Table)}

\section{CROSS SECTIONAL ECHOCARDIOGRAPHY}

Each patient had situs solitus of the atria as shown by a left sided aorta and right sided inferior vena cava draining to the right atrium in subcostal cuts. ${ }^{11}$ Con-

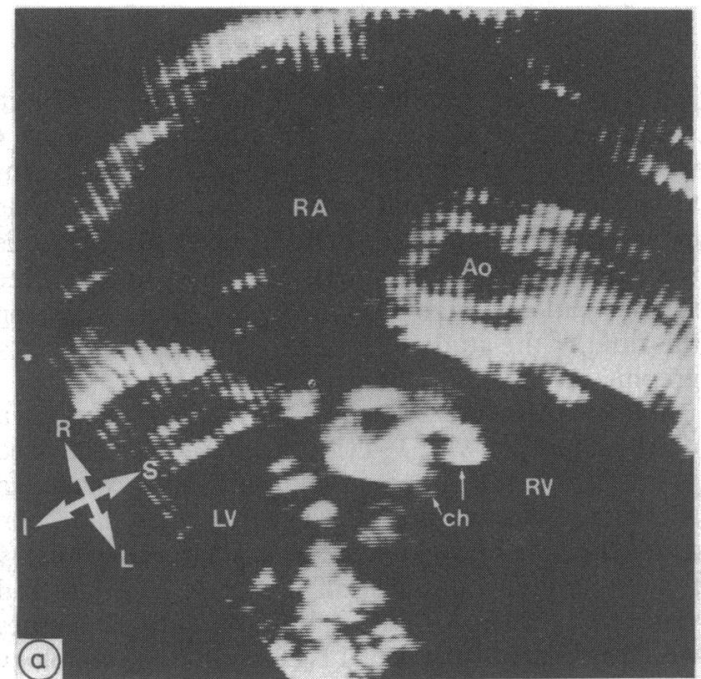

cordant atrioventricular connections were present in seven patients and discordant atrioventricular connections in one. In each case it was impossible to find a plane showing simultaneous and parallel arrangement of the atrioventricular valves and ventricular inflow regions, as described by van Mill et al. ${ }^{9} \mathrm{~A}$ more definitive criterion, in our opinion, was the direct demonstration of a criss cross atrioventricular relation. This could be obtained by positioning the transducer in such a way as to demonstrate from

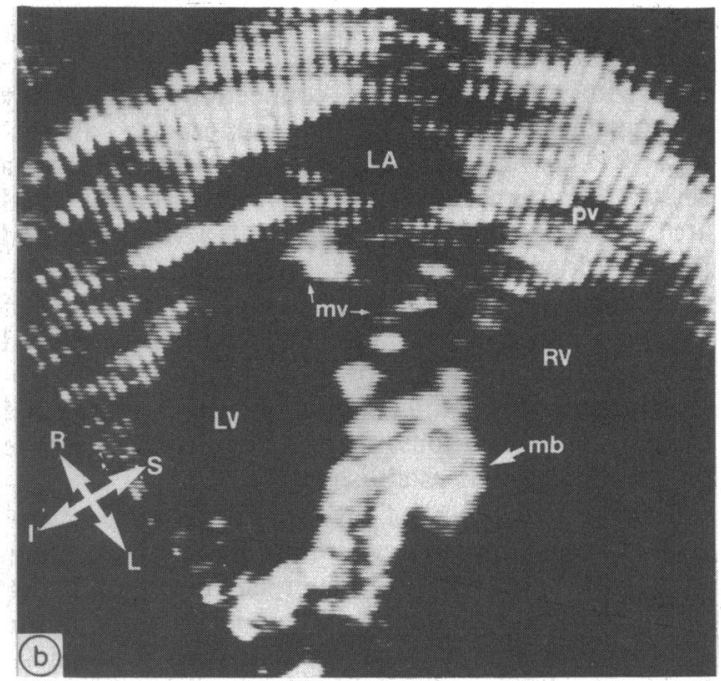

Fig. 1 Cross sectional echocardiograns fram the apex (a) shows connection of the right atrivon $(R A)$ to the right ventricle (RV) with the aortic root $(A o)$ cut in its short axis. The right $(R V)$ and left ventricles $(L V)$ are in superoinferior arrangement and the tricuspid valve has a bright echo on the septal leaflet (see text). (b) shows, from the same transducer position at the apex but with more pasterior angulation, a pulmonary vein (pv) draining to the left atrium (LA) which is connected to the left ventricle (LV). The mitral valve (mv) opens across the plane of right ventricular inflow (see (a)). Note the moderator band (mb) in the right ventricle. $I$, inferior; $L, l e f t ; R$, right; $S$, superior; ch, chordae. 


\begin{tabular}{llllllll}
\hline \multicolumn{2}{ll}{ diac catheterisation } & & & & & \\
\hline s & $\begin{array}{l}A V \\
\text { connection }\end{array}$ & $R A V V$ & $L A V V$ & VSD & RVOTO & $\begin{array}{l}\text { VA } \\
\text { concordance }\end{array}$ & $\begin{array}{l}\text { Gt vessel } \\
\text { position }\end{array}$ \\
\hline tus & $\mathrm{C}$ & $\mathrm{N}$ & $\mathrm{N}$ & Perimembranous & Valvar, subvalvar & $\mathrm{D}$ & Ao anterior and L \\
tus & $\mathrm{C}$ & $\mathrm{N}$ & $\mathrm{S}$ & Perimembranous & - & $\mathrm{C}$ & Ao anterior and L \\
tus & $\mathrm{C}$ & $\mathrm{N}$ & $\mathrm{N}$ & Perimembranous & Valvar, subvalvar & $\mathrm{D}$ & Side by side, Ao to L \\
tus & $\mathrm{C}$ & $\mathrm{N}$ & $\mathrm{S}$ & Perimembranous & - & $\mathrm{D}$ & Ao anterior and L \\
tus & $\mathrm{C}$ & $\mathrm{N}$ & $\mathrm{N}$ & Perimembranous & - & $\mathrm{D}$ & Ao anterior and L \\
tus & $\mathrm{D}$ & $\mathrm{N}$ & $\mathrm{N}$ & Perimembranous outlet & - & ?DORV & Ao anterior and L \\
tus & $\mathrm{C}$ & $\mathrm{O}$ & $\mathrm{N}$ & Perimembranous & - & $\mathrm{C}$ & Ao anterior and L \\
tus & $\mathrm{C}$ & $\mathrm{N}$ & $\mathrm{S}$ & Perimembranous outlet & - & $\mathrm{C}$ & Ao posterior and R \\
\hline
\end{tabular}

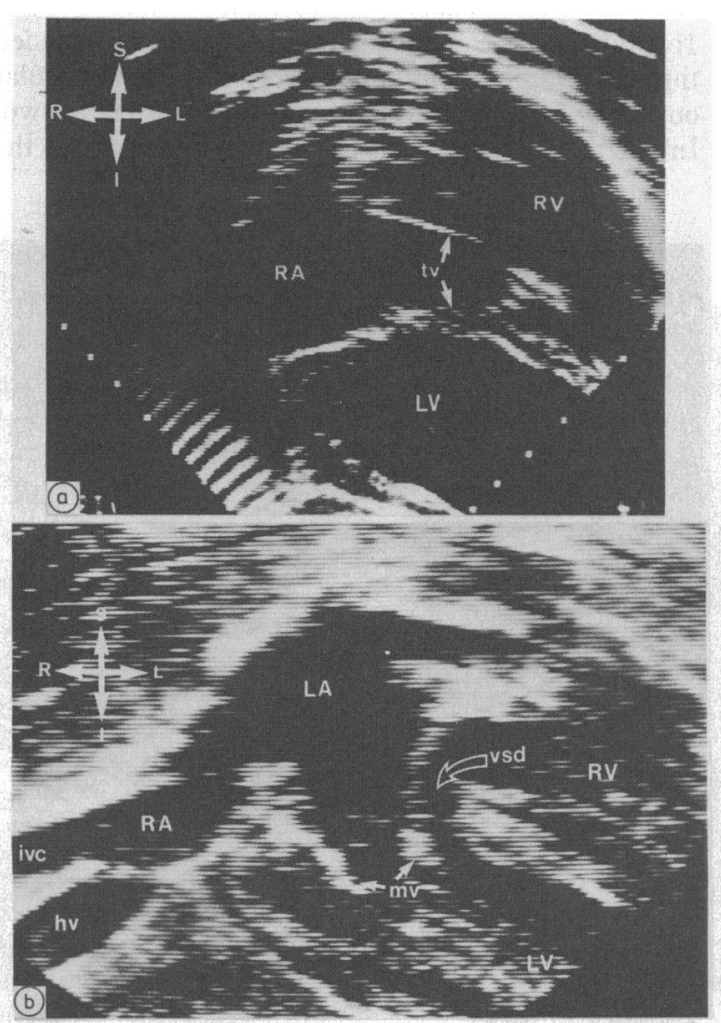

Fig. 2 Cross sectional echocardiograms from the same ransducer position with more anterior angulation in (a) and more pasterior angulation in (b) showing the criss cross arrangement of ventricular inflow region. hv, hepatic vein; I, inferior; ivc, inferior vena cava; $L$, left; LA, left atrivom; mv, mitral valve; $R$, right; $R A$, right atrivm; $R V$, right ventricle; $S$, superior; tv, tricuspid valve; vsd, ventricular septal defect. below each atrium crossing to the contralateral ventricle, with one atrioventricular connection crossing behind the other (Figs. 1 and 2). The precise transducer position required varied from case to case in these highly complex hearts but was usually from the apex or subcostal region. One patient had a straddling tricuspid valve, but no patient had mitral straddling. Three patients, all with concordant atrioventricular connections, had cross sectional echocardiographic evidence of stenosis of the mitral valve (Fig. 3), and one showed a mobile bright echo on the septal leaflet

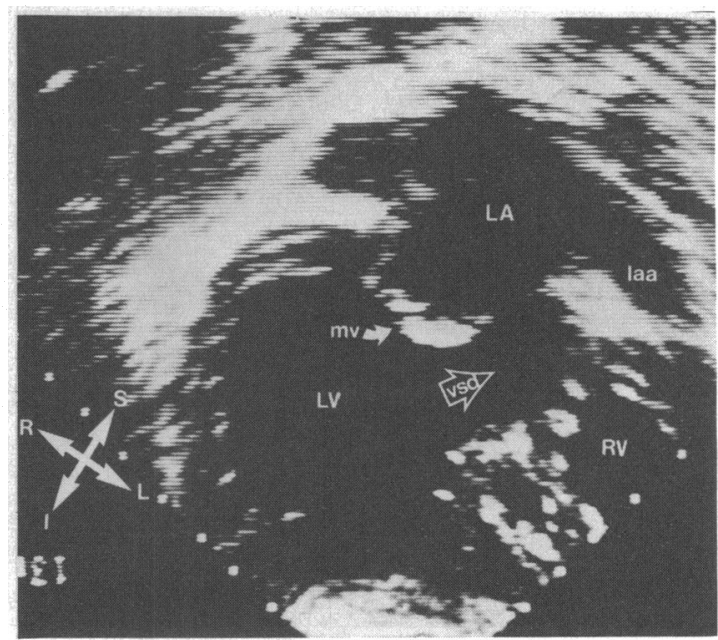

Fig. 3 Cross sectional echocardiogram from the apex showing doming of the stenosed mitral valve (mv) in a patient with a criss cross heart. I, inferior; $L$, left; $L A$, left atrium; laa, left atrial appendage; mo, mitral valve; $R$, right; $R V$, right ventricle; $S$, superior; osd, ventricular septal defect. 


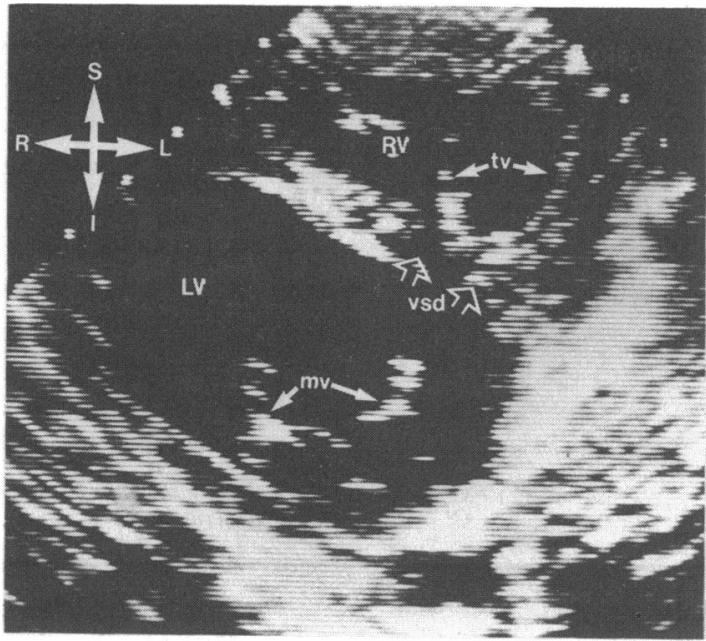

Fig. 4 Cross sectional echocardiogram showing the relative positions of the right $(R V)$ and left ventricles $(L V)$ with left ventricle inferior and slightly rightward of the right ventricle. Note the fishmouth appearance of the mitral valve (mv) and septal attachment of the tricuspid valve (to). I, inferior; $L$, left; $R$, right; $S$, superior; vsd, ventricular septal defect. of the tricuspid valve (Fig. 4). This echo was very similar to one seen in another patient that proved at operation to be ruptured chordae tendineae that had coiled back on themselves..

Because we were uncertain of the precise transducer position used in retrospective studies the cross sectional echocardiographic determination of relative ventricular position was usually not possible retrospectively. In the three patients studied prospectively before angiocardiography (Fig. 5), however, the ventricular positions were correctly predicted as right ventricle slightly anterior, superior, and leftward and left ventricle slightly posterior, inferior, and rightward.

As all our patients had ventricular septal defects that extended to the inlet portion of the septum we could not use offsetting of the atrioventricular valves to identify ventricular morphology. We therefore used either the moderator band as a marker of right ventricle or the fishmouth appearance of the mitral valve in short axis cuts to identify a left ventricle (Figs. $1 b$ and 4). The ventricular septal defect extended through the perimembranous region to the muscular outlet region in five patients and was subaortic in two. In one patient tricuspid tissue protruded through the

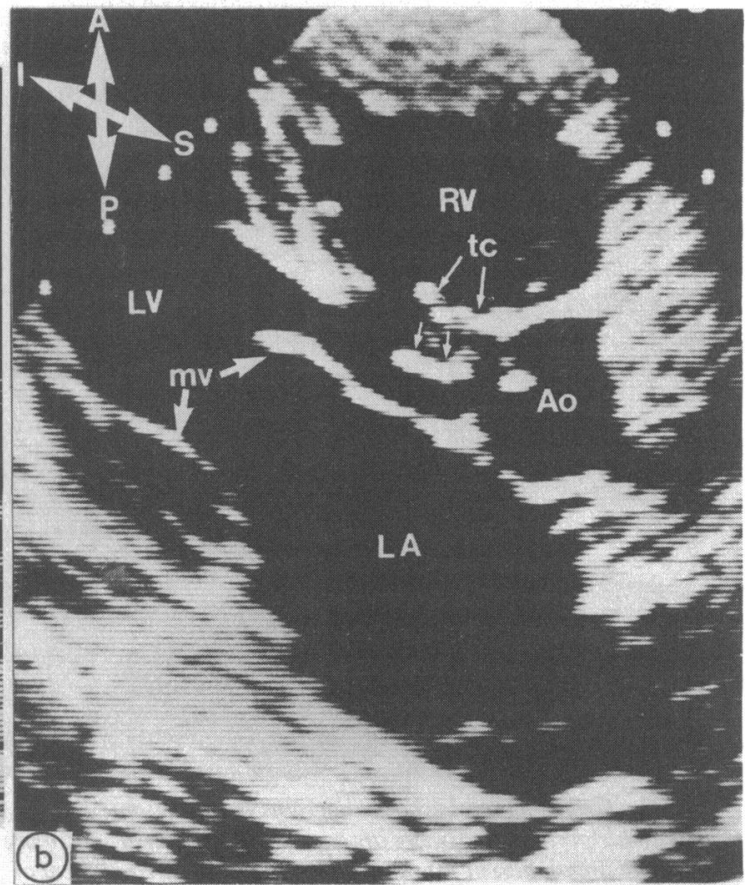

Figs. 5(a) and (b) Long axis cross sectional echocardiograms showing tricuspid valve (tc) tissue prolapsing into the right ventricle $(R V)$ in systole and into the left ventricular $(L V)$ outflow tract in diastole. $A$, anterior; Ao, aortic root; $I$, inferior; $L A$, left atrivon; $m v$, mitral valve; $P$, posterior, $S$, superior. 


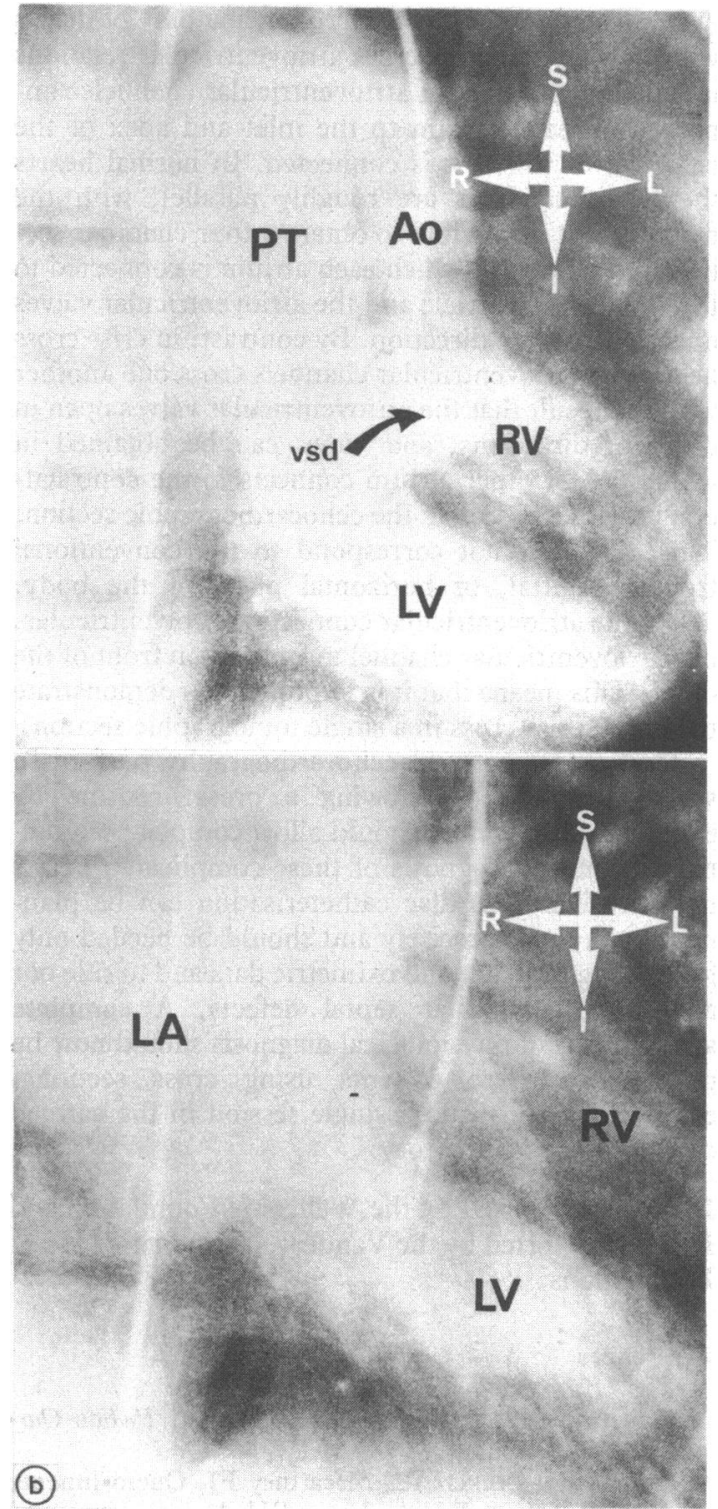

Figs. 6(a) and (b) Anteroposterior cineangiograms from an injection into the left ventricle $(L V)$ with follow through left atrial (LA) opacification in a patient with criss cross heart, atrioventricular concordance, and ventriculoarterial discordance. Ao, aorta; $I$, inferior; $L$, left; $P T$, pubmonary trunk; $R$, right; $R V$, right ventricle; $S$, superior; vsd, ventricular septal defect.

ventricular septal defect to the left ventricular outflow tract in diastole and into the right ventricle in systole (Fig. 5). No patient had subaortic obstruction. Two had subpulmonary obstruction due to fibromuscular tunnel formation, one with associated valvar stenosis.

The origin of the great arteries from the ventricles

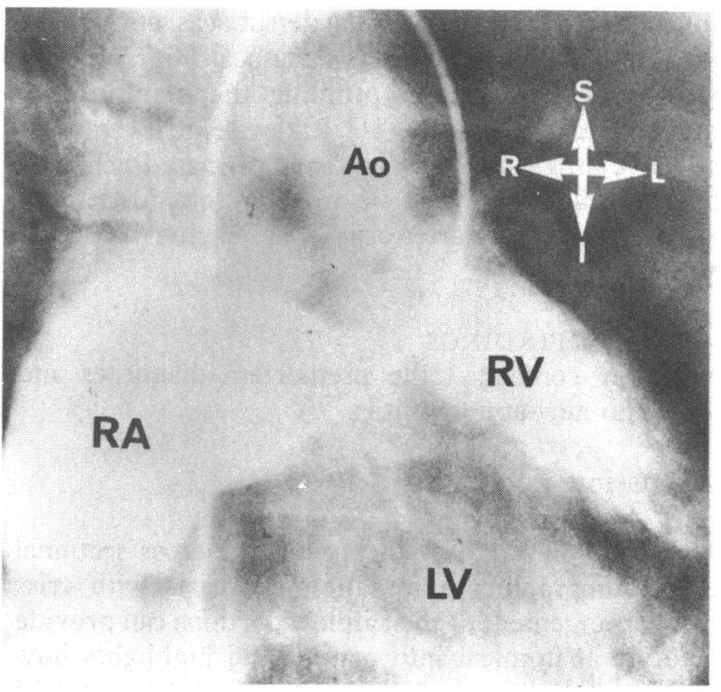

Fig. 7 Cineangiogram from the same patient as in Figs. 6(a) and $(b)$, with injection into the right atrivon. The projection is anteroposterior and comparison with Figure $6(b)$ shows the criss cross arrangement of ventricular inflow regions. Ao, aorta; $I$, inferior; $L$, left; $L V$, left ventricle; $R$, right; $R A$, right atrium; $R V$, right ventricle; $S$, superior.

was easily recognised by echocardiography. There were concordant ventriculoarterial connections in three patients, two with the aorta anterior and slightly leftward of the pulmonary trunk and one with the usual great vessel relation. One patient had double outlet right ventricle with the aorta anterior and slightly to the left of the pulmonary trunk, and four patients had discordant ventriculoarterial connections, three with aorta anterior and to the left of the pulmonary trunk and one with side by side great vessels with aorta to the left. In the three patients studied prospectively the aortic arch was left sided and a persistent ductus arteriosus was excluded.

\section{HAEMODYNAMICS AND ANGIOCARDIOGRAPHY}

(Figs. 6 and 7)

Atrial situs, atrioventricular and ventriculoarterial connections were confirmed by angiocardiography in all patients. (Cineangiocardiography showed the criss cross arrangement when appropriate sites of injection were used.) Pressure measurements confirmed the presence of mitral stenosis in the correct three patients and excluded atrioventricular valve stenosis in the others. Subpulmonary stenosis was confirmed by pressure measurements in one patient and angiocardiography in the other. Though there were no mistakes with echocardiography, ventricular morphology was more obvious on angiocardiograms than on cross sectional echocardiograms. Precise localisa- 
tion of the ventricular septal defect was not always possible with certainty angiocardiographically because of problems in profiling the plane of the interventricular septum. ${ }^{1012}$ Likewise atrioventricular valve straddling was better appreciated echocardiographically. ${ }^{13}$ The aortic arch was left sided and a persistent ductus arteriosus was excluded in all patients.

\section{NECROPSY FINDINGS}

Necropsy confirmed the premortem diagnoses and found no new abnormalities.

\section{Discussion}

This study shows how the systematic cross sectional echocardiographic examination of hearts with criss cross arrangement of their inflow portions can provide accurate anatomical information and highlights how well suited this technique is to the segmental approach in the diagnosis of complex congenital heart disease. In criss cross heart both ventricles and great vessels may be in unexpected positions, but a careful systematic approach will demonstrate the connections, particularly if continuous sweeps between routinely used cross sectional echocardiographic cuts are used. This was exemplified in our study particularly in one patient in whom the aorta was almost directly anterior to the pulmonary trunk and yet the great vessels connected in concordant fashion.

There has previously been only one case report showing the ability of cross sectional echocardiography to make a nearly complete anatomical diagnosis in this condition. Those authors used subcostal cuts alone, parasternal cuts having been unsuccessful. ${ }^{9}$ While we agree that much of the anatomical information may be obtained from these cuts, we found that the precordial views were useful in confirming the impressions gained from the subcostal cuts. Furthermore, precordial cuts were superior in identifying subpulmonary obstruction, great vessel position, and in some cases the actual recognition of the criss cross arrangement of the atrioventricular junction. A further disadvantage of relying on subcostal cuts is that they may not provide a plane showing opening of both atrioventricular valves. If the transducer is not angled sufficiently either anteriorly or posteriorly a false impression of either double inlet ventricle or absent atrioventricular connection may be given, as in the initial echocardiographic diagnosis of the patient studied by van Mill and colleagues. 9 Although we agree that the normal parallel arrangement of the right ventricular and left ventricular inflow tract is not seen in this condition, we have shown how the actual demonstration of the criss cross arrangement is possible echocardiographically.
In understanding the underlying anatomy of hearts with normal and criss cross atrioventricular relations it is helpful to think of atrioventricular channels running from each atrium to the inlet and apex of the ventricle to which it is connected. In normal hearts these two channels are roughly parallel, with the result that it is possible to obtain a four chamber section of the heart in which each atrium is connected to the ipsilateral ventricle and the atrioventricular valves open in the same direction. By contrast, in criss cross hearts the atrioventricular channels cross one another with the result that the atrioventricular valves open in different directions, and views can be obtained in which one or other atrium connects to the contralateral ventricle as seen in the echocardiographic section. This may well not correspond to the conventional frontal, sagittal, or horizontal plane of the body. When the atrioventricular connection is biventricular, one atrioventricular channel must cross in front of the other. This means that it is impossible to demonstrate the entire criss cross in a single tomographic section.

Thus cross sectional echocardiography performed systematically and following a preset routine by experienced operators should allow complete sequential anatomical diagnosis of these complicated hearts non-invasively. Cardiac catheterisation can be planned much more precisely and should be needed only for gaining pressure and oximetric data and to rule out additional ventricular septal defects. A complete anatomical and physiological diagnosis should now be possible in these patients using cross sectional echocardiography and a single session in the cardiac catheterisation laboratory.

PJR was supported by the Wellcome Foundation and FJM is supported by the Vandervell and British Heart Foundations.

\section{References}

1 Anderson RH. Criss cross hearts revisited. Pediatr Cardiol 1982; 3: 305-13.

2 Tynan MJ, Becker AE, Macartney FJ, Quero-Jimenez M, Shinebourne EA, Anderson RH. Nomenclature and classification of congenital heart disease. $\mathrm{Br}$ Heart $\mathrm{f}$ 1979; 41: 544-53.

3 Freedom RM. Superoinferior ventricle and criss cross atrioventricular connections: an analysis of the myth and mystery. Modern Problems in Paediatrics 1983; 22: 48-62.

4 Freedom RM, Culham G, Rowe RD. The criss-cross and superoinferior ventricular heart: an angiocardiographic study. Am F Cardiol 1978; 42: 620-8.

5 Sato K, Ohara S, Tsukaguchi I, et al. A criss-cross heart with concordant atrioventricular-arterial connections. Report of a case. Circulation 1978; 57: 396-400.

6 Schneeweiss A, Shem-Tov A, Blieden LC, Deutsch V, Neufeld HN. Criss-cross heart - A case with horizontal septum, complete transposition, pulmonary atresia and 
ventricular septal defect. Pediatr Cardiol 1982; 3: 325-8.

7 Marino B, Chiariello L, Bosman C, et al. Criss-cross heart with discordant atrioventricular connections. Pediatr Cardiol 1982; 3: 315-8.

8 Attie F, Muñoz-Castellanos L, Ovseyevitz J, et al. Crossed atrioventricular connections. Am Heart $\mathcal{F}$ 1980; 99: 163-72.

9 van Mill G, Moulaert A, Harinck E, Wenink A, Oppenheimer-Dekker A. Subcostal two-dimensional echocardiographic recognition of a criss-cross heart with discordant ventriculoarterial connection. Pediatr Cardiol 1982; 3: 319-23.

10 Macartney FJ, Smallhorn JF. Cross-sectional echocardiography in neonates and children. In: Rowlands $\mathrm{D}$, ed.
Recent advances in cardiology-9. Edinburgh: Churchill Livingstone, 1984: 27-75.

11 Huhta JC, Smallhorn JF, Macartney FJ. Two dimensional echocardiographic diagnosis of situs. $\mathrm{Br}$ Heart $\mathrm{f}$ 1982; 48: 97-108.

12 Bargeron LM Jr, Elliott LP, Soto B, Bream PR, Curry GC. Axial cineangiography in congenital heart disease. Section I. Concept, technical and anatomic considerations. Circulation 1977; 56: 1075-83.

13 Smallhorn JF, Tommasini G, Macartney FJ. Detection and assessment of straddling and overriding atrioventricular valves by two dimensional echocardiography. $\mathrm{Br}$ Heart f 1981; 46: 254-62. 